Journal Article

\title{
School books or wedding dresses? Examining the cultural dissonance experienced by young Gypsy/Traveller women in secondary education'
}

Hamilton, $\mathrm{P}$. 


\title{
School books or wedding dresses? Examining the cultural dissonance experienced by young Gypsy/Traveller women in secondary education
}

\begin{abstract}
Although considerable attention has been given to issues impacting on the educational experiences of Gypsy/Traveller learners in the U.K., most of the literature is oriented towards ethnicity rather than gender. This paper illuminates the experiences of young Gypsy/Traveller women who are engaging with secondary education, and functioning in a dual cultural framework, in a time of increased gender equality. The intersectionality of culture, class and religion, frequently conflict with the notions of gender equality and education, requiring young women to make difficult choices. It is suggested there is an urgent need to problematize and deconstruct stereotypes typically held about Gypsy/Traveller girls, as not all young women feel disengaged, restricted, excluded and in conflict. While some young women, as is their right, wish to conform to cultural-gendered norms, this study has revealed some strong, resilient women who critically challenge values and norms within their community, which negate their right to a full education, to bring about positive change.
\end{abstract}

Key words: culture; cultural dissonance; girls; gypsy/traveller; secondary education

\section{Introduction}

For many years there has been considerable attention given in the United Kingdom (U.K.) to issues impacting Gypsy/Traveller learners. However, the focus of most literature has been oriented towards ethnicity rather than gender (Levinson and Sparkes 2003). Over a decade later and this remains the case; there is limited work available which specifically considers the perceptions held and experiences encountered by Gypsy/Traveller girls in secondary education and the difficult choices being made by this heterogeneous group. Martin Levinson's work in particular, will be drawn upon to inform this study, as it provides rich insight into how family/community dynamics, the intersectionality of both culture and gender, sit alongside mainstream educational expectations. However, he tends to pay more attention to the experiences of Gypsy males. Thus, it is the intention of this paper to plug the gender gap, to contribute to the under-researched area of young female Gypsy/Traveller learners and the complex social and educational dilemmas many are encountering, within the context of cultural dissonance, in a time of increased gender equality. Understanding the potential impact that widening aspirations may have on young women and their family will help to further inform policy and practice so that school practitioners can more effectively support the pastoral and educational needs of this group.

Defining the term 'Gypsy and Traveller' is problematic as it risks incorrectly portraying multiple communities as one homogenous group (Cudworth 2015). Although shared cultural priorities among Gypsy and Traveller groups commonly include: a high regard of the family unit and family decent; clearly defined familial and gender roles; respect for family based learning and self-employment and; commitment to a nomadic lifestyle (Lloyd and McCluskey 2008), the term describes a varied body of communities who have distinct lifestyles, religious and moral beliefs. Furthermore, Levinson (2015) asserts the term 'Gypsy' remains contested as it has pejorative connotations, that the acronym GRT (Gypsy / Roma / Traveller) has little meaning to most Gypsies and, the term 'Traveller' overlooks ethnicity and restricts identity to a lifestyle that may no longer be followed. Whilst acknowledging these distinctions and how challenging it is to find an appropriate term, the phrase 'Gypsy/Traveller' which is used in this paper refers to two diverse peoples i) Travellers of Irish heritage and ii) British Gypsy.

The life experiences of Gypsies/Travellers in the areas of education, employment, health, accommodation and societal prejudice reflect significant disadvantage and marginalisation (Equality and Human Rights Commission 2015; Marcus 2015). The globalised efforts promoting women's rights, including the right to an education, has led to an ideology that educated women are the solution to many of life inequalities (eradicating poverty; promoting community health; eliminating child marriage; controlling family size; preventing violence and war) (Porter 2016). Thus, it is important to consider the concept of empowering women as 'agents of change' and the repercussions that functioning in a conflicting dual cultural framework may have on young Gypsy/Traveller women. The intersectionality of culture, class and religion, frequently conflict with the notions of gender equality and education, and 
resistance is a natural reaction, particularly where a community's identity is based on deeply embedded social norms (Porter 2016).

Concerns over the engagement and attainment of Gypsy/Traveller pupils in the U.K. education system, and a commitment to improve provision for these children, has been acknowledged across a series of consecutive government documents since the 1960s (Cudworth 2008; Myers, McGhee and Bhopal 2010). Yet Gypsy/Traveller pupils continue to fare less well than any other social group at every stage of education (Equality and Human Rights Commission 2015; Derrington 2016). Absenteeism, underachievement and school drop-out rates remain serious educational issues (Bloomer, Hamilton and Potter 2014; Harding 2014). Gypsy/Traveller children are more likely to be excluded, identified as having special educational needs, leave school without qualifications, and are less likely to make the transition to secondary school (Bhopal 2011; Foster and Norton 2012; Office for National Statistics 2014). Thus, it appears that government policies have failed to make sufficient progress for Gypsy/ Traveller children in mainstream education. Levinson (2008) asserts, that in order for any real advancement to be made, more consideration is required of the difficulties young Gypsy/Traveller people encounter in their attempts to manage divergent values and practices at home and school and the wider social and cultural outcomes.

The difficulties Gypsy/Traveller pupils experience in the U.K. are exacerbated by a rigid education system that is performance driven and structured around a statutory curriculum (Cudworth 2008). British law is based on the principle that every child should fully participate in an education system until they reach the compulsory school leaving age of 16 (Education Act 1996) (Harding 2015). It is a system, firmly rooted in the beliefs and aspirations of a non-Gypsy/Traveller culture, which values individualistic and egocentric activity and formal qualifications to acknowledge children's competencies. Such ideology conflicts with Gypsy/Traveller society, which is based on a concept of interdependence and oriented towards group needs/survival rather than individual needs/gain (Jordan 2001; Levinson 2008). Many Gypsy/Traveller parents view secondary education as de-skilling their children, as it reduces integration into the family, resulting in the dilution of knowledge of the cultural, economic and practical skills required (Harding 2014). However, the increasing urbanisation of many Gypsies and Travellers, due to a decline in agricultural work, has resulted in changing needs and skillssets and the growth of more radical ideas (Levinson and Sparkes 2003). There are indications that the lifestyles of many young people who have moved into houses are becoming similar to those of nonGypsy/Traveller children (Levinson 2008). Historically, within Gypsy/Traveller communities a strong male power base has existed. It is perhaps because of the perceived threat to traditional masculine identities that Gypsy/Traveller males have been found to be more resistant to change and find adaptation difficult (Levinson and Sparkes 2003). In comparison, contact with the non-Gypsy/Traveller community has led to an increased awareness among some women of inequities which exist within their society (Levinson and Sparkes 2003).

Although more recently increasing numbers of Gypsy/Traveller women are viewing education as empowering, many young people become dissatisfied at school after the onset of adolescence and either do not continue with secondary education or leave by the age of fourteen (Levinson and Sparkes 2003; Levinson 2015). To understand why this is the case, it is necessary to consider some of the structural features of Gypsy/Traveller society. Gypsy/Traveller people are considered as adults from the age of fourteen, and are expected to work, marry and gain financial independence before the compulsory school leaving age (Bhopal 2011). Boys are expected to learn their father's trade, acquire negotiating abilities and master essential driving skills, whilst young women are encouraged to marry young and resume domestic and childcare duties (Levinson 2008; Derrington 2016). Boys, more than girls, appear to be disillusioned with secondary school (Levinson 2015). Cultural norms around masculinity and learning often result in boys' struggling in the classroom (Save the Children 2014). Family loyalty, and a desire to be regarded as a full community member, remain of greater importance to young men than opportunities presented through the education system (Levinson and Sparkes 2003), causing many to drop out of school early (Levinson 2015). In contrast, girls are reported to mix better in schools, have more non-Gypsy/Traveller friends and participate in the life of a classroom (Jordan 2001). However, girls who have a preference for secondary education may be overruled by parents who feel that learning to look after a home, in preparation for married life, is a more appropriate choice (Levinson 2008). 
Although there can be a sharp distinction of views about the purpose and relevance of schooling among the community and within individual families (Lloyd and McCluskey 2008), there appears to be a close correlation between Gypsy/Traveller pupil and parental opinions towards compulsory education. Attitudes towards primary education are generally positive (Wilkin, Derrington and Foster 2009). However, as young people progress to secondary school there is increased scepticism about its relevancy (Lloyd and McCluskey 2008) and parental anxieties regarding assimilation makes the transition to secondary education uncertain. Such hesitancy is based on a fear that exposure to incompatible beliefs and practices of the dominant society, will erode their child's cultural identity and morals (Bophal 2011; Cudworth 2015). Parents are reported to be particularly concerned about: the lack of understanding in schools of the Gypsy/Traveller culture (Wilkin, Derrington and Foster 2009); low teacher expectations and negative attitudes (Foster and Norton 2012); bullying, racism and discriminatory policies and practices (Derrington 2016); mobility linked to travelling patterns (Devarakonda 2013); exposing their children (teenage girls in particular) to sexual activity, drugs and alcohol (Derrington 2007; Harding 2014) and; an inappropriate curriculum (Cudworth 2008). For many families, cultural patterns and traditional employment remain a priority over school education and once a basic level of literacy and numeracy is attained, many parents consider their children to have achieved all they require from an education (Bloomer, Hamilton and Potter 2014; Rosa' rio, Nu'ñ ez, Azevedo et al. 2014). Learning that has no obvious connection to the home or community may be regarded as oppositional (Levinson 2008). Thus, 'curriculum relevancy', alternative curriculum courses that complement the roles that Gypsies and Travellers traditionally enter, is essential if education is to be continued (Bloomer, Hamilton and Potter 2014). However, a lack of vocational opportunities has been identified (Crozier, Davies and Kim Szymanski 2009), largely due to the government's preoccupation with standards, test results and league tables (Cudworth 2008).

The discord between mainstream schooling and Gypsy/Traveller beliefs can lead to confusion, conflict and difficult choices regarding both education/career aspirations and wider identities for young women who remain at school for longer than the group norm. There is often intolerance of nonconformity (Levinson and Sparkes 2003) and compliance with the norms of mainstream society is often perceived as an act of disloyalty (Levinson 2015). Feelings of shame about members who become assimilated may result in young women self-withdrawing from secondary education. However, it should not be assumed that all Gypsy/Traveller women, who face multiple forms of oppression (gender, culture, economic), will feel restricted, excluded and in conflict (Marcus 2015). As this paper will proceed to show, some young women are developing a high level of resilience and determination in their efforts to deal with the cultural clash caused between home-school interfaces and are critically questioning some of the beliefs within their community, particularly those which impact on their right to a full education, in the hope for positive personal change.

\section{Methods}

This exploratory study, which focuses on gaining insight into the perceptions and experiences of Gypsy/Traveller girls who attend secondary education, was conducted during the autumn and winter term of 2015. Adopting an ethnographical approach, was deemed appropriate because it allows issues to be seen through the eyes and voices of others; providing a rich contextualized understanding of the human experience bound within a cultural and social framework (Gall, M.D., Gall, J.P. and Borg 2007). Within these varied realities and stories are issues and struggles to be analysed (Marcus 2015); an important mechanism for empowering groups at risk of marginalisation, such as young Gypsy/Traveller women.

The fieldwork for this study was undertaken by a manager of a Traveller Education Service (TES) in one local authority of North Wales. The TES manager, who has over ten years' experience of working with the Gypsy/Traveller community, takes a multi-agency approach to her role, which is essentially aimed at fostering relations and improving the attendance and attainment of Gypsy/Traveller pupils. The study is predominantly based on eight in-depth interviews conducted with Gypsy/Traveller girls, aged 13-16 years. Six Gypsy/Traveller mothers were also interviewed as it was considered that this would provide further insight into some of the potential challenges faced by Gypsy/Traveller girls who chose to continue within the secondary education system. All participants were either of white British Gypsy or white Irish Traveller heritage. Fathers/male carers were invited to take part but were either not available at the time of interview or chose not to be involved. As issues regarding the 
education of children are considered to be the mother's role in the Gypsy/Traveller community, this is not unexpected. The sampling framework used was purposeful so as to reflect girls who were known by the TES fieldworker to be engaging with secondary education in an attempt to determine how they negotiated this level of schooling within the context of any cultural dissonance. At the start of the interview process, participants were told that (1) they were going to take part in a research study about secondary education and Gypsy/Traveller girls; (2) data were confidential; (3) there were no right or wrong answers; 4) they had the right to withdraw from the study at any time and; (5) how their responses would be used. Where Gypsy/Traveller mothers had a low level of literacy, this information was read out to them.

Table 1: Participant details

\begin{tabular}{|c|c|c|c|c|}
\hline Parent & Marital status & Number of children & Child interviewed & Place of residence \\
\hline Parent 1 & Married & 4 (2 girls, 2 boys $)$ & Brit, age 15; Selina age, 13 & Traveller site \\
\hline Parent 2 & Separated & 7 (4 girls, 3 boys) & Charity, age 16 & Traveller site \\
\hline Parent 3 & Separated & 8 (5 girls, 3 boys) & $\begin{array}{l}\text { Annmarie, age } 16 ; \\
\text { Mary, age } 14\end{array}$ & Local authority housing \\
\hline Parent 4 & Married & 6 (5 girls, 1 boy) & Shaunie, age 16 & Privately owned house \\
\hline Parent 5 & Married & 4 (2 girls, 2 boys) & Rose, age 15 & Local authority housing \\
\hline Parent 6 & Married & 2 (2 girls) & $\begin{array}{l}\text { Children not interviewed. } \\
\text { Girls under } 11 \text { years }\end{array}$ & Traveller site \\
\hline & & & Margaret, age 14 & Traveller site \\
\hline
\end{tabular}

During the piloting of the semi-structured interview schedules, changes were made to the terminology and sequence of some of the questions. This was deemed necessary to ensure that participants were clear as to the question being asked of them. With regard to sequencing, questions considered to trigger a more emotional response were positioned towards the end of the interview. During the interviews, constant checks were made to ensure that what had been written captured the views of the participants. Critics may assert that the role of the interviewer, because of her employed position, and limited size of the participants involved, are important implications for the validity and reliability of the study. There is the realisation that the interviewer will have had some impact on the research but because of her long established relationship and the trust she has established with the community, it is likely that the girls and mothers were less guarded in their communication with her. However, it is not the purpose of this study to draw firm conclusions, neither does it claim to be representative. Rather, the aim of the study is to offer further insight into this under-researched area.

All 14 interviews were digitally-recorded. The confidentiality of the participants has been assured through the use of pseudonyms. The in-depth interviews lasted between 30-45 minutes in duration and were conducted in the homes of the participants or in an informal venue away from the community. Questions asked of the young women and mothers were similar in attempt to gain multiple versions of parallel phenomena, which could later be analysed to more fully explain the complexities surrounding the secondary education of young female Gypsy/Traveller learners. The young women were asked: What do you want to achieve from going to secondary school? What do you enjoy about secondary school? What age should Gypsy/Traveller girls finish their education? How do your parents feel about you attending secondary school? What does the Gypsy/Traveller community think about you attending secondary school? What are your relationships like with other young people at school? How are you supported by your teachers? Why do some Gypsy/Traveller children drop out of secondary school? What could be done to help Gypsy/Traveller children stay in secondary education for longer? Parents were asked similar versions of the above questions, in addition to: How do you feel about your girls attending secondary education? How have your own experiences of school effected the decisions you have made about your daughter's education?

Data was analysed using the concept of general inductive analysis (Thomas, 2006). Interview transcripts were read and reread several times. The first stage highlighted conceptions (ideas, thoughts, feelings or experiences) expressed by individual participants. The second stage involved noting recurring patterns of meaning and exploring relationships among the emerging conceptions (themes). Finally, the emerging themes were compared to the extant literature to determine relationships and alternative perspectives, giving rise to the development of broader (superordinate) themes. Many of the 
views expressed were contradictory, which highlights the varying experiences of the education system and allegiance to the cultural norms of the Gypsy/Traveller community.

\section{Results and discussion}

The results which follow represent the views and experiences of eight Gypsy/Traveller girls and six Gypsy/Traveller mothers. Through critical analysis of data gathered the following themes emerged: young women's perceptions of education and future aspirations; school relationships; girls and education: family and community perceptions. Some young women seemed accepting of fixed gender and cultural norms from within their families and community, whilst others expressed how such values restricted and oppressed Gypsy/Traveller women. It appears that the dichotomy between the homeschool interfaces makes it challenging for young women to fully engage with the requirements of secondary education whilst also adhering to the expectations of the Gypsy/Traveller culture. Such conflict is resulting in young women having to make difficult choices, which risk threatening both their educational/career aspirations and wider identities. Young women who wish to remain in education are having to compartmentalise (Levinson 2008) their cultural spaces and develop a high level of resilience.

\section{Perceptions of education and future aspirations}

The young women were asked about their views on education and aspirations for the future. Four girls were supportive of secondary education (Mary, Charity, Annemarie, Shaunie) and four were negative about this phase of schooling (Brit, Margaret, Rose, Selina). Characteristics shared by the girls whom valued secondary education appeared to include a supportive mother and secure links with girls from the mainstream community. These girls had ambitions not to marry at a young age but to pursue further studies and a career first. Courses they wished to study after leaving school included psychology; nursing; teaching; health and social care. Unlike Levinson's study (2008), where most young Gypsy people aspired towards occupations which could be used within their own community (for example, hairdresser, cleaner, vet), these girls were interested in training in professions which would take them beyond the Gypsy/Traveller community.

I want to make something of my life. I plan to go to university and get a job as a child psychologist. I like learning new things. I get bored at home. At school I have fun. Everyone has the right to a good and full education. You are allowed to dream for God's sake and you should fulfil that dream. One day, my kids will go right through. (Shaunie)

Mary, Charity, Annemarie and Shaunie stressed the importance of learning more than basic literacy and numeracy. They regarded secondary education as a means to progress to college and university to get a good job, in order to gain financial and social independence. These girls did not only value and argue for a 'good and full education', but were critical of their community's traditional views about the role of education in the lives of Gypsy/Traveller women. Throughout her interview Shaunie, in particular, made a number of powerful comments which illustrated her awareness and frustration of the gender inequities which existed within her community. Much emphasis has been placed on the provision of vocational courses and family based learning for Gypsy/Traveller pupils but as Mary, Charity, Annemarie and Shaunie reveal, some young women are striving to succeed in a formal examination system so that they can pursue careers outside of their community. This serves as an important reminder that there should not be a generalisation of a 'one size fits all' for Gypsy and Traveller children in their education.

The young women who disliked secondary education believed it to be a 'waste of time' because they would never use it as they would be 'looked after' by their future husbands.

School gets in the way of my life. I hate the people and the place. I don't get the work. I don't need a career because I'll marry when I'm 16 and be a wife. My husband will work, so I won't need anything. It's a waste of time going any further when you aren't going to use it. It's too old to be in school past 13. I should be doing the house cleaning not sitting in school. (Brit) 
Rose's comments below, demonstrate a decline in the perceived status of school-based learning and increasing doubt as to how relevant any further education would be to her in the future. Overall, six out of the eight girls, irrespective of whether they enjoyed secondary school or not, thought that by age 12 or 13 most learning had been achieved for Gypsy/Traveller children. This suggests how influential parental views are. Various studies report how many Gypsy/Traveller parents regard the main purpose of schooling to be the provision of a basic grounding of literacy and numeracy (e.g. Myers, McGhee and Bhopal 2010; Bloomer, Hamilton and Potter 2014). As will be illustrated further on in this paper, unsupportive parental attitudes may prevent young women from commencing secondary school or trigger feelings of confusion among those who do attend, despite their ambitions and level of attainment.

I used to really like school but by age 12, you can read and write, everything you need for when you're older, so I've lost interest. In high school it's more serious with exams but I won't need that. So what's the point? (Rose)

\section{School relationships}

Views regarding relationships established at school with teachers and peers outside of the Gypsy/ Traveller community were mixed. Two of the young women (Margaret and Selina) who did not enjoy school discussed how they did not want to make friends with 'gorge' or 'country' children (individuals from the mainstream society) because they did not understand the Gypsy and Traveller culture/s. Margaret, through her expression of inner-toughness, the ability to look after herself in the face of any confrontation, is a typical part of the Gypsy/Traveller learning process; a trait perceived to be essential to group survival (Levinson 2008).

I don't want gorge friends. I'm not bullied, no one would dare bully me but gorge don't get Gypsy ways so it's no use making friends with them. (Margaret)

The young women who were positive about secondary school discussed the importance of the close bonds they had formed with non-Gypsy/Traveller friends, stating that they preferred these relationships (Mary, Charity, Shaunie). However, as Charity shows, some Gypsy/Traveller parents worried that mixing with young people from the mainstream society could expose their daughters to incompatible beliefs and practices, may restrict the growth of such relationships from forming.

I prefer to be with non-Travellers. My non-Traveller friends don't treat me any differently. They include me after school, at weekends, in their house, overnight, even to go on holiday with them. With me being a Traveller I'm not allowed... but next year I'll go. I'll keep asking. I've cut myself off from Traveller girls. Last time I went out with them they made a complete show of me. They called me bad names in front of a group of boys. (Charity)

I have country friends but when they find out who I am, they turn against me. Once, in class, someone talked about Travellers. I said that I was one and people were shocked. One girl was weird with me after finding out I was a Traveller. They think we're all bad. (Rose)

The formation of close bonds with children from the mainstream community, resulting in the severing of links with peers from the Gypsy/Traveller community, requires careful consideration. Gypsy/ Traveller parents cite bullying/racism as their main reason for their rejection of secondary education (Bhopal 2011). Only one young woman (Rose) referred to an incident which involved peers from outside of the Gypsy/Traveller community. As will be discussed in more detail later in this section, all of the young women discussed how conforming to mainstream school expectations and mixing with non-Gypsy/Traveller friends resulted in frequent intra-community conflict/bullying (a response to assimilation into the mainstream community). And, as Gypsy/ Traveller girls tend to stay longer in secondary education than boys, they are more at risk of experiencing such hostility.

Three young women (Mary, Charity, Annemarie) were positive about the supportive relationships they had with their teachers. However, the remaining five girls discussed how teachers did not understand the Gypsy/Traveller culture, made comments about their attendance and treated them 
differently to other pupils. There is evidence to suggest that many teachers operate from a cultural deficit model that problematises the Gypsy/Traveller community (e.g. Lloyd and McCluskey 2008; Devarakonda 2013). Often such negativity is linked to cultural values and behaviours, which are encouraged within the community, being misunderstood or viewed as deviant within the classroom. This, coupled with children's awareness of the apprehension many parents have towards secondary education, risks pupil-teacher relationships being framed by a negative outlook from the outset. Shaunie's comments suggest how some Gypsy/Traveller children may manipulate their parents by playing on their fears regarding mainstream education in order to get out of going to secondary school.

They always have a go at me, ask why I'm not in school. They don't get that I don't want to be there and neither do my parents. A teacher is like a stranger. They're a totally different breed to me. They don't understand my culture, so why speak to them? (Margaret)

Some are nice but you get some real bitches as teachers who treat us different. One complaint and some Traveller kids make out it is twice as bad. A parent will believe their kid, over nonTravellers. Then the kid gets their wish, no more school. (Shaunie)

Positive and secure social links between Gypsy/Traveller pupils and their parents and non-Gypsy/ Traveller pupils and teachers in secondary school has been found to be a key factor in supporting attendance and retention (Derrington 2007). However, establishing a rapport with Gypsy/Traveller children and their families often takes time to achieve (Wilkin, Derrington and Foster 2009) and is reliant on showing understanding of and, respect for, their cultural heritage. Unfortunately, the low levels of attendance of some Gypsy/Traveller children reduces social interaction, thus limiting the bonds formed at school.

\section{Girls and education: family perceptions and community perceptions.}

Shaunie, Charity and Annemarie, who had a strong sense of self and determination, acknowledged that their level of engagement with secondary school had mainly been due to supportive mothers who had wanted them to stay at school to complete formal qualifications (General Certificate of Secondary Education; GCSEs).

Mum says you live once, so make the most of it. She doesn't want me to have the life she has had. She wants me to get a good career. She says I can marry when I want. (Annemarie)

Reasons given by mothers for wanting their daughters to complete secondary education included: learn to read and write; gain GCSEs; mix with Traveller and non-Traveller children; have an opportunity to get a non-traditional Gypsy/Traveller job; allow their daughters to do something more than getting married at a young age. These mothers described positive experiences of their own secondary education and how they had left before gaining any formal qualifications, which they regretted.

I want my girls to have an education because I never had that pleasure. I wish my dad had been stricter and made me go to school. It was my choice to stop going because I wanted to have fun. When I was bullied my dad would say 'you don't have to go again'. I would go home, tell him what happened and then I never had to go back. (Parent 4)

The following comment suggests how some parents might be more open to their daughters staying longer in formal education than their sons. Even where this is the case, parents may feel sceptical as to whether their children, irrespective of any formal qualifications gained, will be perceived as employable by the mainstream community.

If a Traveller girl goes to university and doesn't get a job it's okay because she can marry and be looked after but if a Traveller boy went and didn't get a job he wouldn't know his own culture to do an honest living without robbing. But in the end, boys or girls, they won't get a job in town because they're Travellers. (Parent 1) 
Two of the mothers (Parent 2 and Parent 3), who had been in an abusive marriage, discussed how they were determined that their girls finished secondary education and gained good jobs and were not pressured by the community into marrying at a young age. However, even supportive parents may be wary of their daughters' career aspirations, particularly those that mean moving away to study at university and job opportunities beyond the community, concerned that this will result in the fragmentation of families (Levinson 2015).

My girls say 'I don't want to get married young. I want to go to college and get a career.' I don't want my girls marrying at 15/16. I don't want that kind of life for them. (Parent 2)

Many say 'Why put your girl in college? She should be married by now.' I say 'She can get married at any age as long as she is pure and decent. Why would I want her to marry? To be tortured and have children at 16?' Marrying in the Travelling community means you are owned, like a dog on a lead. You have to tell the man when and where you're going, get his permission and if you get back late you'll get it... (Parent 3)

Annmarie (Parent 3's daughter), acknowledged the high level of support afforded to her by her mother and, perhaps because of her parents' relationship, was critical of the gendered norms within the Gypsy/ Traveller community. Although men and women suffer partner abuse, aggression and the suppression of emotions, are often traits highly valued in communities where a strong male power base dominants; where violence may be used as a way of exerting masculinity (Marchbank and Letherby 2014; Save the Children 2014). There is evidence to suggest that many women from the Gypsy/Traveller community, who report domestic violence, will have suffered more severely and over a longer period than other women (Equality and Human Rights Commission 2009). The harmful impact of domestic violence is exacerbated when women face other forms of discrimination such as racism and poverty (Harrison and Thiara 2013) or if they have lived in a closed community and had little education; these women may assume that most men are violent and domestic violence is normal (Clark 2009). Furthermore, many Gypsy/Travellers have traditional views on marriage and, with divorce uncommon, a woman leaving a marriage is often ostracised by her family and community. Clark (2009) argues that change is beginning to happen; that more women are seeking equality in their relationships and more mothers are assisting their daughters in leaving violent relationships. For women, such as Parent 2 and Parent 3, who face layers of disadvantage, children represent their possibility of achievement and power (Marchbank and Letherby 2014). The determination to see their daughters enjoying a better life than they themselves have experienced might result in resilient women who feel empowered to challenge oppressive gendered norms. However, as has been found in this study and also by Levinson and Sparkes (2003), there can be significant intolerance by some females within the community against oppositional beliefs and practices which might put cultural norms and gender identities at risk. Five out of the eight girls discussed how their mothers did not want them to attend school, believing them to be too old, concerned they were missing out on learning essential domestic duties and that 'too much schooling would make their daughters unsuitable for marriage', as also reported by Levinson (2008).

Mum went to court over me not attending, now she hates it. I only go to keep us out of trouble with the law. She says I should be at home learning to cook and clean or I won't get a husband. Full-time school just does not work for our community. (Margaret)

Three mothers appeared very much opposed to sending their children to secondary school referred to negative experiences they themselves had faced as learners in this phase of education. Parent 1 was anxious that her daughter would be left floundering at school due to her low level of literacy. Parent 5 did not want her girls to experience the bullying she herself had encountered. Parent 6 claimed she would home tutor her daughters as she did not want them exposed to alcohol, drugs and sexual activity.

When I was in school, my teacher knew I couldn't read but made me read to the whole school. The other children looked at me as though I were a fool. Now I avoid school. (Parent 1)

In secondary school our kids get bullied more for being Travellers, treated differently, and called a 'Gypsy', so parents pull them out. (Parent 5) 
Children smoke, drink, do drugs and learn about sex. Boys could get them to do stuff. When I was in school we were put altogether for sex education. My mum didn't like that, so pulled me out. I tell my girls 'what do you do if a boy tries to kiss you?' They say 'kick him'. You've got to teach them this early. My girls won't be going. I'll home tutor them. (Parent 6)

The above concerns are not new, rather they are widely documented within the literature base, as are guidelines available to schools to address such issues, in order to improve the experiences of Gypsy/ Traveller pupils. However, Charity asserts that irrespective of any measures that local authorities or schools attempt to introduce, it all rests on the support that young women get from their immediate family as to the extent to which they engage with education and whether or not they complete secondary school.

If Travellers want to leave school early they will. If the family don't want them there, it makes it hard for them to stay, no matter what you do to try and change things. (Charity)

Shaunie shows how there can be disagreement among mothers and fathers about the education of their children. She discussed at length how supportive her mother was in allowing her to stay in secondary school beyond the 'norm age' but that her father found this decision difficult to tolerate.

A Traveller girl is only born to cook, clean, get married and have babies. Because parents were reared in the olden days they stick to tradition. It's not fair. Mum's fine but dad says 'stop talking about school, you're home now, so pretend to be a Traveller even if you prefer to be a country person. You should be married now, thinking about your wedding, not about getting your homework in on time.' But that's not me. Everyone says be proud of who you are but I'm not. I'd prefer to have a non-Traveller life. (Shaunie)

A recurring issue that all of the young women and mothers referred to during the interview process was the high level of intra-community conflict experienced by individuals who remained in secondary education. Some of the young women described how they had been bullied by other Gypsy/Traveller children and made to feel guilty by adults within their family and wider community about attending school because it went against cultural norms. Such disapproval may unnerve a child or parent who might be contemplating this phase of education, making the transition to secondary school uncertain. It may also result young women who are attending secondary education finishing before the compulsory school leaving age.

When I go to the site, lots of girls have a go at me. Even the younger ones bully me. They call me 'little school girl'. One said if I didn't give up school and get married soon I would be left on the shelf. I ignore it, it's my life. Culture is important to me as it's who I am but I want to get a good job and be independent. I don't want to be some stay at home wife. (Annemarie)

Traveller girls who don't go to school show off on Facebook and bully the ones that go. (Selina)

Bullying from the community is hard because Travellers aren't meant to go to high school. It's a bad thing. You're seen as a country person. You're not proud of going against the culture. I used to want to stay and found it hard when my family called me 'school girl' but I realise now I won't need GCSEs, so I agree, I shouldn't be there. (Brit)

Four mothers discussed how they were classed as 'country people' and their daughters taunted for being 'little school girls.' Three mothers explained how they knew they were being deviant, by going against the culture, in their choice to let their daughters stay on at secondary school. These mothers described how, in order to deal with the criticism, they had 'cut themselves off' from mixing with the Gypsy/Traveller community (as had Shaunie and Charity).

I keep myself to myself. I don't mix. If I can get my kids to college, I've done my duty. Too many leave younger than 16, they barely know anything. (Parent 2) 
There is a strong sense of pride for the Gypsy/Traveller culture and there can be feelings of significant dishonour about members who chose to deviate from the cultural norms. Thus it is important to consider the repercussions of such perceived deviance and the impact this may have individuals socially, emotionally and educationally. It appears that in order for girls like Shaunie to be able to follow their aspirations, they will have to develop a high level of resilience and perseverance and effective negotiation skills to navigate their way through entrenched family and community views.

With a historical focus on black racism and more currently forms of white racism, stemming from the cultural clash of diverse white ethnic groups settling within the U.K., the impact of intracommunity bullying may not be fully recognised or understood by school practitioners. Such intracultural discord is similar to a study undertaken by Hansen, Melhus, Høgmo et al. (2008) which showed how many of the indigenous Sami people of Norway, who assimilated into the Norwegian majority's language, occupations and cultural way of life, received significant criticism from the traditionally minded members of their community. This frequently resulted in double discrimination for assimilated Sami, from both the Norwegian majority and the Sami community (Hansen, Melhus, Høgmo et al. 2008). This seems to have been the case for Rose and Brit, who by staying longer in education than most of their Gypsy/Traveller peers, had made friends with children from the mainstream community. However, they had lost these friendships after their cultural identity had been exposed (Rose) or when their friends had become annoyed with the flexible timetable offered to Gypsy/Traveller pupils (Brit). Thus, young women who chose to comply with the dominant mainstream society by remaining at school for longer than the group norm and, whom form close relationships with non-Travellers, not only risk jeopardising their Gypsy/Traveller identity, but also becoming socially isolated from both social groups.

The cultural conflict typically encountered by Gypsy/ Traveller women may result in some (1) assimilating into the dominant culture by adopting its values and lifestyles, resulting in the loss of their own cultural heritage (for example, Charity); (2) separation, resisting/rejecting the dominant culture by challenging teachers, avoiding 'country' peers, self-excluding from school in an attempt to preserve their own cultural identity (for example, Margaret); (3) integration, balancing their loyalties by assimilating whilst at school but maintaining their own lifestyle and values for intra-group use (for example, Rose) (Berry 2001). Theories regarding hybridisation and multiple identities may offer a way forward for young Gypsy/Traveller women living between two conflicting cultural spaces. However, Levinson (2008) cautions that it is not easy for young people to develop such identities and live alongside more traditional members who may regard the change as an act of group betrayal (the example of Shaunie and her father illustrates this point). He asserts that the hybrid is forced into selecting one milieu or the other and that it is difficult to negotiate the way back into the home and wider community (Levinson 2015); such young women risk being ostracised by their family and community. And, unfortunately as Rose and Parent 1 allude, when individuals choose to deviate from Gypsy/Traveller society, there is no guarantee they will be fully accepted into mainstream society, after they have decided to 'risk family and community relationships', in order to take up the opportunities which are presented to them within secondary education.

\section{Conclusion}

This paper, which focuses on the under-researched area of young Gypsy/Traveller women in secondary education, offers additional insight into the complex social and educational choices being made by this group of learners, who are functioning in a dual cultural framework. Further understanding of the potential impact that widening educational and career aspirations may have on young women and their family has also been gained. The strength of this paper is that it pulls together and builds upon information which remains briefly scattered throughout the literature base.

For many young women, the cultural dichotomy between the Gypsy/Traveller culture and the non-Gypsy/Traveller culture, makes it problematic for them to fully engage with the requirements of secondary education whilst also conforming to cultural norms and expectations. The intersectionality of race, ethnicity, culture and religion, frequently conflict with the notions of gender equality and education, exposing young Gypsy/Traveller women to multiple challenges and barriers, which require them to make difficult choices; choices which risk threatening both their educational aspirations and wider identities. Strict cultural norms appear to restrict the physical, emotional and mental space (Marcus 2015) which allow young Gypsy/Traveller women to continue and flourish in secondary education. However, there is a need to problematize and deconstruct stereotypes held about Gypsy/ 
Traveller girls, as not all young women feel disengaged, restricted, excluded and in conflict. While some young women, as is their right, have a strong preference to conform to cultural and gender norms, this study has also revealed pro-active and resilient women who are critically questioning norms within their community, which negate their right to a full education. So, the questions to be asked are i) what causes some young women to fight to retain their school books whilst others opt for wedding dresses? and ii) what are the repercussions for young women who choose to remain in secondary education?

What becomes clear from the research is that a gradual shift in attitudes towards education is occurring. The increased urbanisation of Gypsies/Travellers is resulting in more young women becoming aware of the gender inequalities which exist within their society and the widening opportunities available to them, which are being presented in secondary school. It is clear that some young women view education a tool that can empower them to make positive personal change. These young women expressed a strong desire to remain in education post 16, believing that this would open career opportunities beyond the Gypsy/Traveller community, enabling them to be socially and financially independent. They did not want to be limited to the role of wife and mother at a young age. Instead, they were endeavouring to seek agency and choice, by challenging long standing cultural beliefs, values and expectations, which they argued, restricted and oppressed Gypsy/Traveller women. Despite significant intra-community criticism, a result of their decision to continue with their studies, they appeared to be holding on tightly to educational aspirations. Young women, who sit between two contrasting milieus, risk becoming changed individuals (hybrids), with differing beliefs, behaviours and expectations, which may not be tolerated by more traditionally minded family and community members. However, these women appeared to have developed resilience, determination, negotiation skills and were compartmentalising their cultural spaces, to deal with the lack of congruence between home and school. Secure friendships with children from the mainstream community and a strong, supportive mother (some mothers were themselves trying to overcome oppressive relationships), seem to be protective factors helping women to succeed beyond the realms of marriage and childrearing. A challenge for parents who wish to support the widening aspirations of their daughters, is how to respond to new opportunities, whilst managing the potential backlash associated with dishonouring cultural value-systems. One way some mothers had dealt with criticism was to isolate themselves and their family from the community. However, worthy of consideration is how some mothers, who have become isolated, will respond to the threat of further family fragmentation brought about by their daughter's request to move away to university and enter employment outside the Gypsy/Traveller community.

In contrast, some young Gypsy/Traveller women were accepting of fixed cultural and gender norms. This may be because the traditional customs of the Gypsy/Traveller community provides a secure sense of identity but it could be that some women are also fearful of the repercussions of deviating from cultural norms. All of the women involved in the study referred to a high level of intracommunity conflict. Many described how they were jeered or ostracised because of engaging in secondary school. Girls who had enjoyed the first few years of secondary education, discussed how they had later lost interest and felt disengaged. Unsupportive, ambivalent and disapproving family members may cause young women who are attending school to feel confused and guilty, causing them to withdraw, despite their ambitions and level of attainment. Why, when faced with increasing pressure to succeed in an education system that measures success in terms of GCSE grades, which Gypsies/ Travellers are typically told are of no use to their lives, would young women risk such disapproval from their family and wider community? Moreover, many young women and mothers felt that teachers lacked understanding and were often negative of the Gypsy/Traveller culture, thus positive bonds which have been found to keep children in school for longer (Derrington 2007) were lacking.

There is a pressing need for future research to ascertain more detailed information regarding the strategies used by some Gypsy/Traveller women to cope with intra-community criticism. However, this needs to be done without pathologizing Gypsies/Travellers as a victim group as this does little to reflect the reality of some young women's strength to make complex choices between acceptance and rejection of what is available from the secondary education system (Jordan 2001). Such investigations need to be situated within critical gender and race equity pedagogies and intersectional approaches. There also needs to be consideration of the repercussions associated with changing expectations, widening aspirations and the press to keep Gypsy/Traveller women in education. As this study suggests, the decision to continue with secondary education may result in young Gypsy/Traveller women becoming socially excluded from one society or both. Furthermore, after fulfilling their educational 
aspirations and gaining qualifications, there is no guarantee they will be afforded high status and respected employment opportunities within mainstream society.

The findings of this study have problematized reductionist and stereotypical thinking about Gypsy/Traveller women, as such a philosophy risks limiting young women's orientations towards learning, achievement, behaviour, subject and career choices. Whatever initiatives are implemented to support Gypsy/Traveller pupils, it is important not to make assumptions about the needs and aspirations of young women - there should not be the generalisation that 'one size fits all'. Some young women may want to continue with their studies post 16 in order to pursue non-traditional career pathways, whilst others will want to remain at home to learn the traditions of the Gypsy/Traveller culture; some young women may wish to study gender typical vocational subjects (e.g. care, hairdressing, cookery), whilst others will want to complete formal qualifications in academic subjects; some may want to see their cultural heritage incorporated into the curriculum, whilst others may wish for this to go unnoticed and; some young women will only make friends with Gypsy/Traveller children, while others prefer to establish friendships outside their community.

Improving educational opportunities for young Gypsy/Traveller women ultimately begins with the family unit. However, if teachers are aware of external and internal structural inequalities, as well as the cultural priorities and moral obligations which may put pressure on young Gypsy/Traveller women, then they can use this understanding to foster supportive relationships and strategies which empower those who wish to flourish and make personal change. Teacher education has a fundamental role to play in preparing teachers with a critical but sensitive orientation towards the cultural and gender discourses which may impact on young Gypsy/Traveller women. Whilst there is a need for cultural sensitivity, there needs to be an appropriate balance with the rights of girls/young women. There needs to be ongoing commitment from teachers to (1) reflect on how their own gendered, social, religious and ethnic positioning may impact on learners; (2) raise their understanding of cultural and gender issues and to use this knowledge to support and empower individuals who risk being marginalised (3) acknowledge the complex narrative and possible impact brought about by the intersectionality of gender, race, culture, religion and social class (4) work with Gypsy/Traveller parents, to break down cultural and gender barriers and reinforce the benefits of education for young women. There is a need for teachers to become more reflexively aware of the impact of cultural dissonance and constraints of gendered discourses which limit experiences and opportunities for young Gypsy/Traveller women, and to incorporate multiple ways of thinking, working and supporting this group of learners in secondary education.

\section{Acknowledgements}

I would like to thank the Traveller Education Service Manager for allowing me to use some of the transcripts she collated as part of a Master's Degree in Education. Your generosity has helped to contribute to an under-researched area in the field of gender studies. 


\section{References}

Berry, J.W. (2001), ‘A psychology of immigration', Journal of Social Issues, Vol. 57 (3), 615-631.

Bhopal, K. (2011), 'This is a school, it's not a site': teachers' attitudes towards Gypsy and Traveller pupils in school in England, U.K.', British Educational Research Journal, Vol. 37 (3), 465483.

Bloomer, F., Hamilton, J. and Potter, M. (2014), 'Challenges and barriers in primary school education: the experiences of Traveller children and young people in Northern Ireland', Education Citizenship and Social Justice, Vol. 9 (1), 3-18.

Clark, J. (2009), On the road to change: dealing with domestic violence in Gypsy and Traveller groups. Available at http://www.theguardian.com/lifeandstyle/2009/aug/14/gypsiestravellers-domestic-abuse

Crozier, G., Davies, J. and Kim Szymanski, K. (2009) 'Education, identity and Roma families: teachers' perspectives and engagement with insetrom training', Intercultural Education, Vol. 20 (6), 537-548.

Cudworth, D. (2008), 'There is a little bit more than just delivering the stuff. Policy, pedagogy and the education of Gypsy/Traveller children', Critical Social Policy, Vol. 28 (3), 361-377.

Derrington, C. (2007), 'Fight, flight and playing white: an examination of coping strategies adopted by Gypsy Traveller adolescents in English secondary schools', International Journal of Educational Research, Vol. 46 (6), 357-367.

Derrington, C. (2016), Supporting Gypsy, Roma and Traveller pupils, in Richards, G. and Armstrong, F. (eds.), Teaching and Learning in Diverse and Inclusive Classrooms. pp 41-51. Oxon: Routledge.

Devarakonda, C. (2013), Diversity and Inclusion in Early Childhood. London: Sage.

Equality and Human Rights Commission (2009), Inequalities Experienced by Gypsy and Traveller Communities: A review. Report 12. Manchester: Equality and Human Rights Commission.

Equality and Human Rights Commission (2015), Is Britain Fairer? The State of Equality and Human Rights. London: HMSO.

Foster, B. and Norton, P. (2012), 'Educational equality for Gypsy, Roma and Traveller children and young people in the U.K.' The Equal Rights Review, Vol. 8, 85-112.

Gall, M.D., Gall, J.P. and Borg, W.R. (2007), Educational Research: An introduction. Eighth Edition. Berkshire: Allyn and Bacon.

Hansen, K., Melhus, M., Høgmo, A. and Lund, E. (2008), 'Ethnic Discrimination and Bullying in the Sami and Non-Sami populations in Norway: the Saminor study', International Journal of Circumpolar Health, Vol. 67 (1), 99-115.

Harding, S. (2014), 'Social exclusion: cultural dissonance between Travellers and non-Travellers in British secondary schools', Journal of Student Engagement: Education Matters, Vol. 4 (1), $25-34$.

Harrison, C. and Thiara, R. (2013), Children and young people affected by domestic violence and abuse: the role of schools promoting safety, well-being and protection, Purdy, N. (ed.), Pastoral Care 11-16. pp 96-127. London: Bloomsbury.

Jordan, E. (2001), 'Exclusion of Travellers in state schools', Educational Research, Vol. 43 (2), 117132.

Levinson, M. (2008), 'Not just content, but style: Gypsy children traversing boundaries', Research in Comparative and International Education, Vol.3, (3), 235-249.

Levinson, M. (2015), 'What's the plan? What plan? Changing aspirations among Gypsy youngsters, and implications for future cultural identities and group membership', British Journal of Sociology of Education, Vol. 36 (8), 1149-1169.

Levinson, M. and Sparkes, A. (2003), 'Gypsy masculinities and the school-home interface: exploring contradictions and tensions', British Journal of Sociology of Education, Vol. 24, (5), 587-603.

Lloyd, G. and McCluskey, G. (2008), 'Education and Gypsies/Travellers: contradictions and significant silences', International Journal of Inclusive Education, Vol. 12 (4), 331-345.

Marchbank, J. and Leterby, G. (2014), Introduction to Gender: Social Science Perspectives. Second edition. Oxon: Routledge. 
Marcus, G. (2015), 'Marginalisation and the Voices of Gypsy/Traveller Girls', Cambridge OpenReview Educational Research e-Journal, Vol. 1 (2), 55-77.

Myers, M., McGhee, D. and Bhopal, K. (2010) 'At the crossroads: Gypsy and Traveller parents' perceptions of education, protection and social change', Race, Ethnicity and Education, Vol. 13 (4), 533-548.

Office for National Statistics (2014) '2011 Census Analysis, What does the 2011 Census tell us about the Characteristics of Gypsy and Irish Traveller in England and Wales', Statistical Release. Available at: http://www.ons.gov.uk/ons/rel/census/2011-census-analysis/what-does-the2011-census-tell-us-about-the-characteristics-of-gypsy-or-irish-travellers-in-england-andwales-/index.html

Porter, S. (2016), 'Girls' education, development and social change', Policy Futures in Education, Vol. 14 (5), 517-538.

Rosário, P., Nu'ñez, J.C., Azevedo, R., Cunha, J., Pereira, A. and Mourão, R. (2014), 'Understanding Gypsy children's conceptions of learning: a phenomenographic study', School Psychology International, Vol. 35 (2), 152-166.

Save the Children (2014), Engendering Transformational Change. Save the Children Gender Equality Program Guidance and Toolkit. Available at: http://resourcecentre.savethechildren.se/sites/default/files/documents/executive_summary_ge nder_equality_toolkit_execsummary.

Thomas, D.R. (2006), 'A general inductive approach for analysing qualitative evaluation data' American Journal of Evaluation, Vol. 27 (2), 237-246.

Wilkin, A., Derrington, C. and Foster, B. (2009), Improving the Outcomes for Gypsy, Roma and Traveller Pupils: Literature review (DCSF Research Report RR077). London: Department for Children, Schools and Families. 